\title{
Transmembrane Glucose Transport in Skeletal Muscle of Patients with Non-Insulin-dependent Diabetes
}

\author{
Riccardo C. Bonadonna, ${ }^{\star \star}$ Stefano Del Prato, ${ }^{\ddagger}$ Maria Pia Saccomani, ${ }^{5}$ Enzo Bonora, ${ }^{\ddagger}$ Giovanni Gulli, \\ Eleuterio Ferrannini, ** Dennis Bier," Claudio Cobelli, ${ }^{5}$ and Ralph A. DeFronzo* \\ ${ }^{*}$ Metabolism Unit of the Consiglio Nazionale delle Ricerche Institute of Clinical Physiology at the University of Pisa, Italy, ${ }^{\S}$ Department \\ of Electronics and Informatics, University of Padua, Italy; "Division of Metabolism, Washington University School of Medicine, \\ St. Louis, Missouri; and ${ }^{\ddagger}$ Division of Diabetes, University of Texas Health Science Center and Audie L. Murphy \\ Veterans Administration Hospital, San Antonio, Texas
}

\begin{abstract}
Insulin resistance for glucose metabolism in skeletal muscle is a key feature in non-insulin-dependent diabetes mellitus (NIDDM). Which cellular effectors of glucose metabolism are involved is still unknown. We investigated whether transmembrane glucose transport in vivo is impaired in skeletal muscle in nonobese NIDDM patients. We performed euglycemic insulin clamp studies in combination with the forearm balance technique (brachial artery and deep forearm vein catheterization) in six nonobese NIDDM patients and five age- and weightmatched controls. Unlabeled D-mannitol (a nontransportable molecule) and radioactive 3- $O$-methyl-D-glucose (the reference molecular probe to assess glucose transport activity) were simultaneously injected into the brachial artery, and the washout curves were measured in the deep venous effluent blood. In vivo transmembrane transport of 3-O-methyl-D-glucose in forearm muscle was determined by computerized analysis of the washout curves. At similar steady-state plasma concentrations of insulin $(\sim 500 \mathrm{pmol} /$ liter $)$ and glucose $(\sim 5.15 \mathrm{mmol} /$ liter ), transmembrane inward transport of 3-O-methyl-D-glucose in skeletal muscle was markedly reduced in the NIDDM patients $\left(6.5 \times 10^{-2} \pm 0.56 \times 10^{-2} \cdot \mathrm{min}^{-1}\right)$ compared with controls $\left(12.5 \times 10^{-2} \pm 1.5 \times 10^{-2} \cdot \min ^{-1}, P<0.005\right)$. Mean glucose uptake was also reduced in the diabetics both at the whole body level $(9.25 \pm 1.84$ vs. $28.3 \pm 2.44 \mu \mathrm{mol} / \mathrm{min}$ per $\mathrm{kg}, P$ $<0.02)$ and in the forearm tissues $(5.84 \pm 1.51$ vs. $37.5 \pm 7.95$ $\mu \mathrm{mol} / \mathrm{min}$ per $\mathrm{kg}, P<0.02)$. When the latter rates were extrapolated to the whole body level, skeletal muscle accounted for $\sim \mathbf{8 0 \%}$ of the defect in insulin action seen in NIDDM patients. We conclude that transmembrane glucose transport, when assessed in vivo in skeletal muscle, is insensitive to insulin in nonobese NIDDM patients, and plays a major role in determin-
\end{abstract}

Dr. Stefano Del Prato was on leave from the Division of Diabetes and Metabolic Diseases, University of Padova School of Medicine, Padova, Italy. Dr. Enzo Bonora was on leave from the Division of Metabolic Diseases, University of Verona School of Medicine, Verona, Italy. Dr. Giovanni Gulli was on leave from the Department of Endocrine and Metabolic Sciences (DISEM), University of Genova School of Medicine, Genova, Italy.

Address correspondence to Dr. Riccardo C. Bonadonna, Istituto di Fisiologia Clinica-C.N.R., Via Savi 8, I56100 Pisa, Italy.

Received for publication 10 December 1991 and in revised form 12 January 1993.

J. Clin. Invest.

(C) The American Society for Clinical Investigation, Inc.

0021-9738/93/07/0486/09 \$2.00

Volume 92, July 1993, 486-494 ing whole body insulin resistance. (J. Clin. Invest. 1993. 92:486-494.) Key words: limb balance $\bullet$ insulin resistance $\bullet$ hyperglycemia

\section{Introduction}

Patients with non-insulin-dependent diabetes mellitus $(\text { NIDDM })^{1}$ are characterized by defects in pancreatic $\beta$ cell function and insulin action on target tissues (1).

Skeletal muscle has been shown to be the principal site of insulin resistance, defined as a reduced ability to metabolize glucose after insulin stimulation (2-4). Before being phosphorylated, glucose must be transported across the cell membrane via a facilitated diffusion system, mediated by specific transporters.

Recently, it has been recognized that transmembrane glucose transport actually is mediated by a family of glucose transporters (5). Each isoform of glucose transporter has a characteristic tissue distribution and a physiologic regulation of its own. For instance, the insulin-sensitive glucose transporter (glut 4) is expressed only in the insulin-dependent organs ( skeletal muscle, heart, adipose tissue) (6-9).

Insulin accelerates transmembrane glucose transport in the insulin-sensitive tissues, primarily by recruiting glucose transporters from an intracellular pool and causing their insertion into the plasma membrane, although some evidence in favor of an insulin-mediated increase in the affinity of glucose transporters for glucose also exists (10-15). Therefore, transmembrane glucose transport is a primary candidate step for causing skeletal muscle insulin resistance in non-insulin-dependent diabetics.

In an earlier study, morbid obesity, irrespective of diabetes, was shown to be associated with a defect in insulin-mediated glucose transport in human muscle strips in vitro. Diabetes itself was not associated with the impairment in glucose transport (16). A recent report by Andréasson et al. showed that glucose transport was defective at supraphysiological insulin concentrations in human muscle strips taken from elderly nonobese diabetic patients; however, the impairment in glucose transport in these patients was less than evident at physiological insulin concentrations (17). In a number of recent reports (18-22), transcription and translation of the gene for the insulin-sensitive glucose transporter were found, almost uniformly (20), to be normal in muscle biopsies obtained from non-insulin-dependent diabetics, although glucose transport activity was not simultaneously assessed. To the best of our knowledge,

1. Abbreviations used in this paper: Hct, hematocrit; NIDDM, non-insulin-dependent diabetes mellitus. 
there are no published papers in which the in vivo activity of glucose transport in skeletal muscle of patients with NIDDM has been evaluated.

Recently, we developed a dual tracer method to assess transmembrane glucose transport in vivo in human skeletal muscle (23) and constructed the in vivo dose-response curve of glucose transport to insulin (24). In this study, we used the same approach to assess whether transmembrane glucose transport in human skeletal muscle is resistant to insulin in NIDDM.

\section{Methods}

Subjects. We studied six subjects with NIDDM and five healthy controls matched for age and weight. All of the diabetic subjects fulfilled the criteria for the diagnosis of diabetes as established by the National Diabetes Data Group (25). All patients but one, who was newly diagnosed, were treated with oral sulfonylurea agents. Their medication was discontinued at least $8 \mathrm{~d}$ before the study. All subjects were free from any major disease other than diabetes mellitus and were taking no other medications. None of the normal subjects had a family history of diabetes. All subjects consumed an isocaloric diet containing $>200 \mathrm{~g}$ of carbohydrate/ $\mathrm{d}$ for at least $3 \mathrm{~d}$ before the study. Other relevant characteristics of the study subjects are summarized in Table $\mathbf{I}$.

All investigations were carried out in the postabsorptive state after a 10-12-h overnight fast. The purpose, nature, and potential risks of the study were explained to all subjects, and informed, written consent was obtained before their participation. The protocol was reviewed and approved by the Human Investigation Committee at the University of Texas Health Science Center at San Antonio, TX.

Experimental design. All studies were begun at 8:30 a.m. On the evening before the study, all of the diabetic patients were admitted to the Clinical Research Center and received an overnight intravenous infusion of insulin (0.6-1.5 pmol/min per $\mathrm{kg}$ ), which was adjusted every hour in order to slowly achieve and maintain normoglycemia. Therefore, diabetic and normal subjects were studied at comparable plasma glucose concentrations. On the morning of the study, catheters were introduced percutaneously into the brachial artery and retrogradely into an ipsilateral deep forearm vein draining forearm muscle. The tip of the deep forearm vein catheter was advanced for a distance of 2 in. from the puncture site, and could not be palpated in any of the subjects. Previous studies have documented that such catheter placement allows sampling of the muscle bed perfused by either the radial or ulnar artery (26). Catheter patency was maintained by a slow infusion of normal saline. To exclude blood flow to the hand, a pediatric sphyg-

Table I. Relevant Characteristics of the Study Groups

\begin{tabular}{lcc}
\hline & Controls & Diabetics \\
\hline Number & 5 & 6 \\
Gender (M/F) & $4 / 1$ & $5 / 1$ \\
Ethnicity (MA/A) & $3 / 2$ & $3 / 3$ \\
Age (yr) & $42 \pm 6$ & $49 \pm 5$ \\
Body mass index (kg/m ${ }^{2}$ ) & $24.5 \pm 0.77$ & $24.8 \pm 1$ \\
Fasting plasma glucose (mmol/liter) & $5.51 \pm 0.91$ & $10.9 \pm 1.22^{*}$ \\
Fasting plasma insulin (pmol/liter) & $40.8 \pm 6$ & $72.2 \pm 11^{\ddagger}$ \\
Systolic blood pressure (mmHg) & $128 \pm 3.6$ & $131 \pm 4.9$ \\
Diastolic blood pressure (mmHg) & $83 \pm 2.4$ & $81 \pm 3$ \\
\end{tabular}

Table entries for continuous variables are mean \pm SEM. M, male; F, female; MA, Mexican American ancestry; A, white Caucasian ancestry. ${ }^{*} P<0.01$, diabetics vs. controls; ${ }^{\ddagger} P<0.05$, diabetics vs. controls. momanometric cuff was inflated about the wrist to $100 \mathrm{mmHg}$ above the systolic pressure for $2 \mathrm{~min}$ before and during each sampling inter$\mathrm{val}$, as well as for $2 \mathrm{~min}$ before and $10 \mathrm{~min}$ after tracer injection. A third catheter was inserted into a contralateral arm vein for the infusion of test substances.

After a 70-min basal period, a euglycemic clamp was performed for 140 min (27). Human regular insulin (Humulin; Eli Lilly Co., Indianapolis, IN) was infused intravenously in a prime-continuous fashion at a rate of $240 \mathrm{pmol} / \mathrm{min}$ per $\mathrm{m}^{2}$ of body surface area in order to achieve plasma insulin concentrations in the physiological range. Plasma glucose was clamped at the basal level by a variable infusion of $20 \%$ glucose based on the negative feedback principle (27). At $-70,-30,-15$, $0,10,40,60,80,100$, and $140 \mathrm{~min}$, arterial and venous blood samples were obtained simultaneously for the determination of plasma glucose concentration. Arterial blood samples were obtained in the basal state and during the euglycemic clamp for the determination of plasma insulin and plasma FFA concentrations. At -55 and +110 min, a bolus of unlabeled D-mannitol ( $\sim 580 \mu \mathrm{mol})$ plus $3-O-\left[{ }^{14} \mathrm{C}\right]$ methyl-D-glucose (4-8 $\mu \mathrm{Ci}$ ) was rapidly $(3 \mathrm{~s})$ injected into the artery via the same syringe. Frequent blood samples (every 10-30 s) were drawn from the deep vein for 10-15 min thereafter. Forearm volume was measured in all subjects by water displacement. Forearm specific gravity was assumed to be 1 . Forearm blood flow was measured by indocyanine green dye dilution at $-70,-30,-15,+40,+80,+100$, and $+140(28)$.

The radioactive tracer $\left(3-O-\left[{ }^{14} \mathrm{C}\right]\right.$-methyl-D-glucose) was purchased from New England Nuclear (Boston, MA) and was tested to be sterile and pyrogen free before use.

Analytical determinations. Plasma glucose concentration was determined in duplicate by the glucose oxidase method on a Beckman Glucose Analyzer II (Beckman Instruments, Inc., Fullerton, CA). Plasma insulin concentration was measured by radioimmunoassay as previously described (29). Plasma FFA concentration was determined by a commercial kit (Wako Chemical GmbH, Neuss, FRG). Indocyanine green dye concentration was determined spectrophotometrically at $810 \mathrm{~nm}(28)$. To determine $3-O-\left[{ }^{14} \mathrm{C}\right]$ methyl-D-glucose concentrations in deep venous effluent blood, plasma was precipitated according to Somogyi and aliquots of the supernatant were evaporated to dryness, reconstituted with water, mixed with scintillation fluid, and counted for ${ }^{14} \mathrm{C}$ radioactivity in a dual channel liquid scintillation counter with external standard correction (Beckman Instruments, Inc.). Known volumes of all tracer infusates were added to plasma samples obtained from the same subject before the injection of the tracers, and plasma radioactivity was determined after Somogyi precipitation as described above (23).

Plasma D-mannitol concentration in deep venous effluent blood was determined as follows. To $400 \mu \mathrm{l}$ of plasma were added $50 \mu \mathrm{l}$ of a 50 -mM solution of $1-\left[{ }^{13} \mathrm{C},{ }^{2} \mathrm{H}_{2}\right]$ mannitol as an internal standard. Thereafter, $600 \mu \mathrm{l}$ of cold acetone was added to precipitate plasma proteins. After centrifugation in the cold, the supernatant was transferred to a 2-ml conical vial and evaporated to dryness with a dry nitrogen stream at $40^{\circ} \mathrm{C} .100 \mu \mathrm{l}$ of a $1: 1(\mathrm{vol} / \mathrm{vol})$ mixture of acetic anhydride/pyridine was added, the vial was closed with a teflon-lined cap, and the mannitol hexaacetate derivative was permitted to form overnight at room temperature. Under these conditions, the formation of mannitol hexaacetate is complete. Subsequently, $1 \mu \mathrm{l}$ of the derivatization solution was injected into a $2 \mathrm{~m}$ by $2 \mathrm{~mm}$ glass column packed with 4\% OV-225 on Gas-Chrom Q ( $100-120$ mesh) and the mannitol hexaacetate was separated from other plasma constituents by isothermal gas chromatography at $240^{\circ} \mathrm{C}$. The gas chromatographic effluent was introduced into a model 3300 mass spectrometer (Finnigan MAT, San Jose, CA) where the mannitol hexaacetate was ionized by electron impact at 120 electron volts. Ions at $\mathrm{m} / \mathrm{z} 375$ and $\mathrm{m} / \mathrm{z} 378$ (and their corresponding isotope clusters) representing the [M-acetate $]^{+}$ions of unlabeled and $1-\left[{ }^{13} \mathrm{C},{ }^{2} \mathrm{H}_{2}\right]$ mannitol, respectively, were monitored and the ion current areas were quantified by computer, invariably to a precision of $\pm 0.5 \%$ or better. After appropriate corrections for the small amount of unlabeled mannitol in the internal standard and the naturally occurring stable isotopic contributions to the 
$\mathrm{m} / \mathrm{z} 378$ ion, the plasma content of unlabeled mannitol was calculated from the known quantity of the added $\left[{ }^{13} \mathrm{C},{ }^{2} \mathrm{H}_{2}\right]$ internal standard and the ratios of the ion current areas according to conventional "reverse isotope dilution" equations. Aliquots of the infusates were treated in the same way as the plasma samples, and the concentration of D-mannitol in the injected volume was accordingly quantitated. The measured linearity of the method spans four orders of magnitude, from 40 $\mu \mathrm{M}$ to $400 \mathrm{mM}$ of plasma mannitol concentration.

Calculations. Whole body uptake of exogenous glucose was calculated over the final $60 \mathrm{~min}$ of the clamp according to the following formula:

uptake $=$ glucose infusion rate + pool correction,

where the pool correction takes into account the change in the whole body glucose pool, as estimated from the change in plasma glucose concentration (27). This correction was always $<5 \%$ of the glucose infusion rate during the insulin clamp. Since tritiated glucose was not used to quantitate hepatic glucose production, whole body uptake of exogenous glucose represents a low boundary for whole body glucose metabolism. However, we have previously shown that hepatic glucose output is completely suppressed in controls and diabetics at this insulin concentration (30). Therefore, during the insulin clamp, the uptake, as measured by the above formula, is a close estimate of the rate of whole body glucose metabolism. ciple:

Forearm glucose uptake was quantitated according to the Fick prin-

uptake $=[$ arteriovenous concentration gradient $] \times$ blood flow,

where blood glucose concentration was estimated from plasma glucose concentration and the hematocrit (Hct) according to the following formula (31):

blood concentration $=$ plasma concentration $\times(1-0.3 \mathrm{Hct})$.

Forearm blood flow was measured by indocyanine green dye dilution in the deep vein according to the following formula:

blood flow rate $=$ dye infusion rate $/($ dye concentration $) /(1-\mathrm{Hct})$.

It should be emphasized that, by the law of mass conservation, under steady-state conditions forearm glucose uptake equals the irreversible metabolism of glucose by the cells. In forearm tissues, this irreversible metabolism is equivalent to the rate of glucose phosphorylation. Strictly speaking, steady-state conditions are verified when all glucose masses and fluxes in the forearm are time invariant (32). In these experiments, we were able to document near constancy of glucose fluxes and concentrations at the inlet (artery) and the outlet (deep vein ) of the forearm in the basal state and during the final $60 \mathrm{~min}$ of the euglycemic clamp studies, and we assumed that this reflected an analogous state in the inaccessible regions inside the forearm, specifically the intracellular glucose mass and glucose phosphorylation rate. There- fore, in this study forearm glucose uptake is considered to be equal to the rate of glucose phosphorylation, and the two terms are used interchangeably.

Measurement of glucose transport. Our method to measure transmembrane glucose transport in vivo is based on the principle that $D$ mannitol is freely diffusible into the extracellular space but does not permeate the cell, whereas 3-O-methyl-D-glucose is transported by the same specific carriers as D-glucose (33) but does not undergo any further metabolism. Therefore, the kinetic differences between the two tracers essentially reflect the activity of the glucose carriers in transporting 3-O-methyl-D-glucose into and out of the intracellular space. Since forearm blood flow is $\sim 1 \%$ of cardiac output $(3,23,28)$, recirculation of any substance injected into the brachial artery is negligible. Under such circumstances the forearm can be assimilated to an isolated organ perfused by a nonrecirculating medium. This experimental setting fulfills the criteria for the application of the multiple tracer dilution technique, which has been in use for over three decades to study transendothelial and cellular transport in isolated perfused preparations of animal organs $(34,35)$.

Fig. 1 shows a typical dual tracer washout curve of D-mannitol and 3-O-methyl-D-glucose in a control subject and in a diabetic patient after hyperinsulinemia. These washout curves are shown because, owing to an almost unique coincidence, the kinetics of D-mannitol is similar in these two individuals, and therefore, by simple visual inspection it is possible to appreciate a substantial difference in 3-O-methylD-glucose kinetics between the two subjects. Within this time interval, at each time point the concentration of 3-O-methyl-D-glucose in the deep vein is lower than D-mannitol. From a qualitative viewpoint, the difference between the two tracers is roughly proportional to the activity of transmembrane glucose transport. However, transmembrane traffic of 3-O-methyl-D-glucose is composed of two transmembrane unidirectional fluxes: glucose transport into and glucose transport out of the cell. At this simplistic level of analysis, these two unidirectional fluxes cannot be discriminated, nor can quantitative comparisons be made within and between individuals and/or groups.

A linear flow compartmental model has been used to measure fractional 3-O-methyl-D-glucose transport into and out of the cell from the two tracer dilution curves. The model itself, its numerical identification, and the mathematical and statistical criteria used to assess its validity have been described in detail in an earlier publication (23). We also reported that the model predicted the correct values for both L-glucose (the extracellular marker used in the experiments reported in that paper) and 3-O-methyl-D-glucose mean transit times, as well as for the size of the sampling compartment (forearm deep vein), thereby fulfilling three different physioanatomic criteria of validity (23). Salient features of the model are its ability to describe blood flow heterogeneity in the vascular structure, diffusion in the interstitial fluid, and kinetics of 3-O-methyl-D-glucose transport into and out of the cell. The kinetic parameters provided by the model include the rate constants (minutes $^{-1}$ ) of transmembrane 3-O-methyl-D-glucose transport into, $k_{\text {in }}$ ( $k_{92}$ in the terminology used in reference 23), and out of, $k_{\text {out }}\left(k_{29}\right.$ in the terminology used in reference 23 ), the cell in each individual. Note

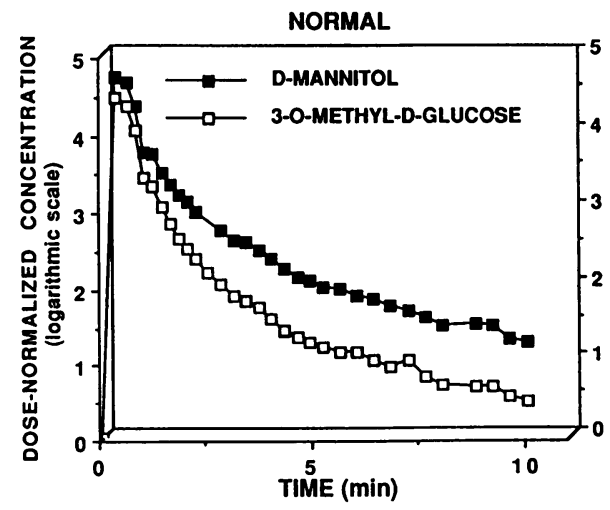

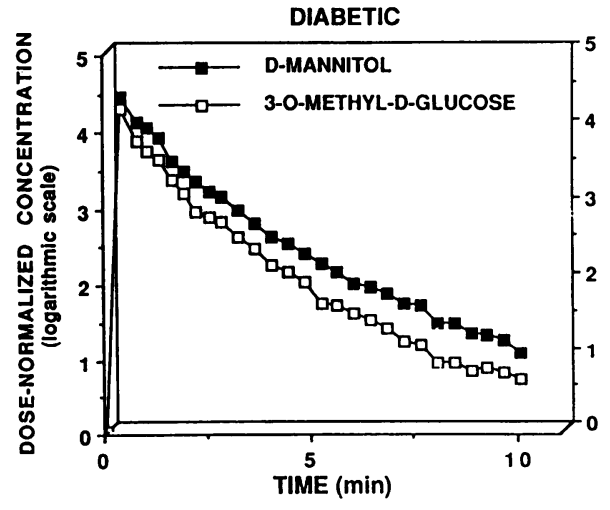

Figure 1. Typical washout curves in the deep venous effluent blood of a control subject (left) and a diabetic patient ( right) after hyperinsulinemia. The D-mannitol and 3-Omethyl-D-glucose concentrations are normalized to the respective doses and expressed in a logarithmic scale in order to allow visual, direct comparison between the kinetic behavior of the two substances. 
that these rate constants measure the fractional rates of 3-O-methyl-Dglucose transport; that is, $k_{\text {in }}\left(k_{\text {out }}\right)$ measures the fraction of extracellular (intracellular) 3-O-methyl-D-glucose mass which is transported per minute inside (outside) the cell. Both $k_{\text {in }}$ and $k_{\text {out }}$ (units: minutes ${ }^{-1}$ ) are different from the $K_{\mathrm{m}}$ (concentration at which glucose transport reaches half-maximal rate; units: millimoles per liter) and the $V_{\max }$ (maximal rate of glucose transport; units: millimoles per minute) of glucose transport, as well as from the turnover number (number of substrate molecules transported per minute by a single transporter molecule when the transporter is the rate-limiting factor; units: minutes ${ }^{-1}$ ) of the glucose transporters. It can be shown $(36,37)$ that the $k_{\text {in }}$ of 3-O-methyl-D-glucose transport is related to the $K_{\mathrm{m}}$ and $V_{\max }$ of glucose transport by the following equation:

$$
k_{\mathrm{in}}=(1 / \mathrm{ECV}) *\left(V_{\max }^{\prime}\right) *\left\{1 /\left[K_{\mathrm{m}}^{\prime}+S_{\mathrm{EC}} *\left(K_{\mathrm{m}}^{\prime} / K_{\mathrm{m}}\right)\right]\right\},
$$

where ECV is the extracellular volume of distribution of 3- $O$-methyl-Dglucose, $V_{\max }^{\prime}$ is the $V_{\max }$ of 3-O-methyl-D-glucose transport, $K_{\mathrm{m}}^{\prime}$ is the $K_{\mathrm{m}}$ of 3-O-methyl-D-glucose transport, $S_{\mathrm{EC}}$ is glucose concentration in the extracellular fluid, and $K_{\mathrm{m}}$ is the $K_{\mathrm{m}}$ of glucose transport. Thus, during a euglycemic insulin clamp, assuming that the extracellular volume of distribution of 3-O-methyl-D-glucose is invariant and that any change in the kinetic parameters of 3-O-methyl-D-glucose transport is accompanied by parallel changes in the kinetic parameters of glucose transport, $k_{\text {in }}$ can increase as a consequence of an increase in transport $V_{\max }^{\prime}$ (increased transport capacity) or a decrease in transport $K_{\mathrm{m}}^{\prime}$ (increased transport affinity).

It is of interest to examine the mutual relationship of $k_{\text {in }}$ and $k_{\text {out }}$ in a symmetric transport system. Muscle glucose transport is believed to be such a system (33). By applying a process of derivation analogous to the one used for Eq. 1 and assuming that glucose transport in skeletal muscle is symmetric (33), it can be shown that:

$$
k_{\text {out }}=(1 / \mathrm{ICV}) *\left(V_{\max }^{\prime}\right) *\left\{1 /\left[K_{\mathrm{m}}^{\prime}+S_{\mathrm{IC}} *\left(K_{\mathrm{m}}^{\prime} / K_{\mathrm{m}}\right)\right]\right\},
$$

where ICV is the intracellular volume of distribution of 3-O-methyl-Dglucose and $S_{\mathrm{IC}}$ is the glucose concentration inside the cell. Therefore, assuming that ICV does not change, $k_{\text {out }}$ can increase as a consequence of either an increase in $V_{\text {max }}^{\prime}$ or a decrease in $K_{m}^{\prime}$ of transport, or, since intracellular glucose concentration is not clamped, a decrease in the intracellular glucose concentration.

Eqs. 1 and 2 can be rewritten as follows:

$$
k_{\text {in }}=(1 / \mathrm{ECV}) *\left(V_{\max }^{\prime} / K_{\mathrm{m}}^{\prime}\right) *\left[K_{\mathrm{m}} /\left(K_{\mathrm{m}}+S_{\mathrm{EC}}\right)\right]
$$
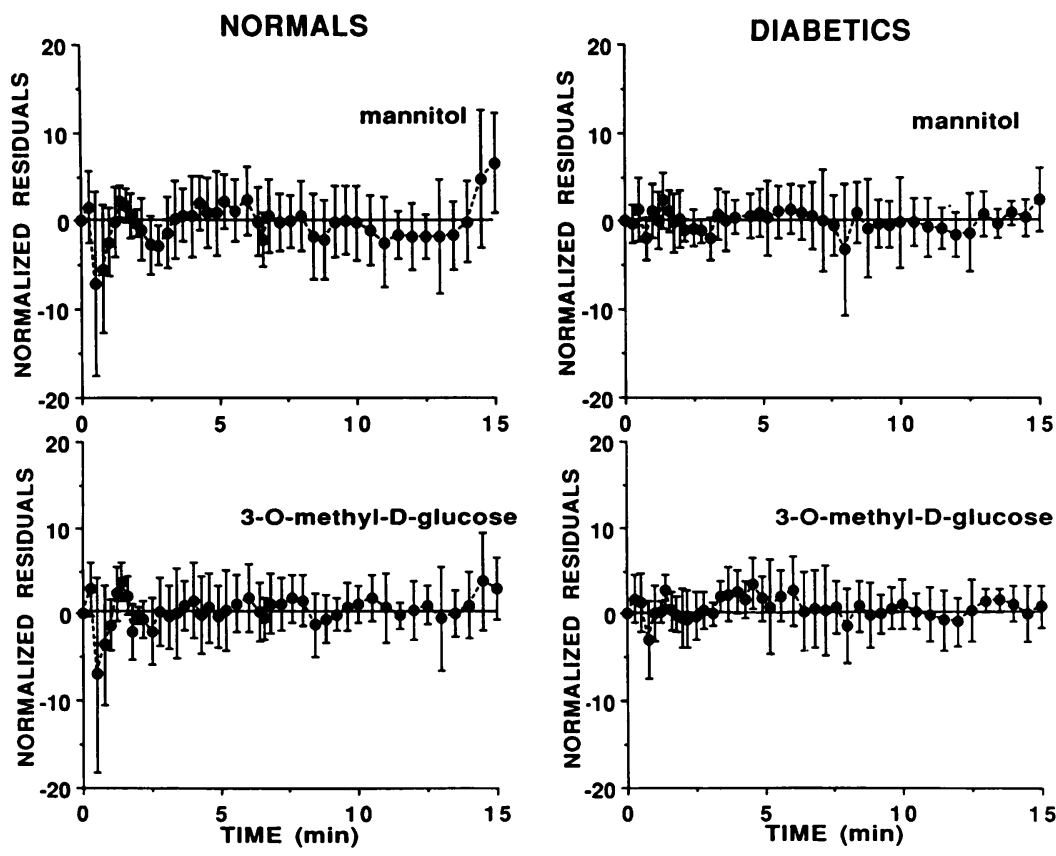

Figure 2. Normalized residuals (mean $\pm \mathrm{SD}$ ) of D-mannitol (upper graphs) and 3-O-methyl-D-glucose (lower graphs) concentrations in control (left panels) and diabetic (right panels) subjects. The residuals are calculated as the difference between the measured and the modelpredicted values divided by the standard deviation of the measurement. Good fit is guaranteed by random scattering of the residuals around zero, with no point being significantly different from zero. 
Statistical analysis. All data in the text are presented as means \pm SE. Differences within and between groups were tested by Student's $t$ test for paired and unpaired data, respectively. Correlation coefficients were computed by standard formulas (41).

\section{Results}

Plasma glucose, insulin, and FFA levels. Basal plasma glucose concentration was similar in NIDDM patients and controls ( $5.51 \pm 0.91$ vs. $5.12 \pm 0.12 \mathrm{mmol} /$ liter). Basal plasma insulin concentration was higher in NIDDM patients than in controls ( $174 \pm 24$ vs. $40.8 \pm 6 \mathrm{pmol} /$ liter, $P<0.01$ ), reflecting the intravenous insulin administration that was needed to maintain normoglycemia in the diabetic patients. Basal plasma FFA concentration was lower in NIDDM patients than in controls ( $473 \pm 42$ vs. $706 \pm 97 \mu \mathrm{mol} /$ liter, $P<0.05$ ), presumably because of the higher insulin concentration.

During the insulin clamp, arterial glucose concentration was $5.1 \pm 0.55$ and $5.22 \pm 0.33 \mathrm{mmol} /$ liter in NIDDM patients and controls, respectively, whereas arterial insulin concentration was elevated to $531 \pm 102$ and $472 \pm 22 \mathrm{pmol} /$ liter in the two groups $(P<0.01$ vs. baseline values for both $)$, respectively. In all insulin clamp studies the plasma glucose concentration was maintained within $8 \%$ of the desired goal, with coefficients of variation $<5 \%$. During hyperinsulinemia, arterial FFA concentration fell to a similar plateau in both NIDDM patients and controls $(203 \pm 41$ vs. $170 \pm 40 \mu \mathrm{mol} / \mathrm{liter}, P<0.01$ vs. respective baseline values for both).

Whole body and forearm glucose uptake. During the insulin clamp, whole body uptake of exogenous glucose was lower in NIDDM than in control subjects $(9.25 \pm 1.84$ vs. $28.3 \pm 2.44$ $\mu \mathrm{mol} / \mathrm{min}$ per $\mathrm{kg}$ of body weight, $P<0.02$ ), thus documenting the presence of insulin resistance in these patients.

In the basal state, forearm blood flow was similar in NIDDM patients and controls $(42.0 \pm 6.5$ vs. $38.8 \pm 3.2 \mathrm{ml} / \mathrm{min}$ per $\mathrm{kg}$, respectively). Hyperinsulinemia did not significantly change forearm blood flow either in diabetics or controls ( $41.7 \pm 5.6$ vs. $40.2 \pm 3.2 \mathrm{ml} / \mathrm{min}$ per $\mathrm{kg}$, respectively).

Basal rates of forearm glucose uptake (phosphorylation) were not significantly different in NIDDM patients and controls $(7.36 \pm 1.21$ vs. $4.38 \pm 1.16 \mu \mathrm{mol} / \mathrm{min}$ per $\mathrm{kg}$ of forearm tissues). During the insulin clamp, forearm glucose uptake rose significantly in controls $(37.5 \pm 7.95 \mu \mathrm{mol} / \mathrm{min}$ per $\mathrm{kg}, P$

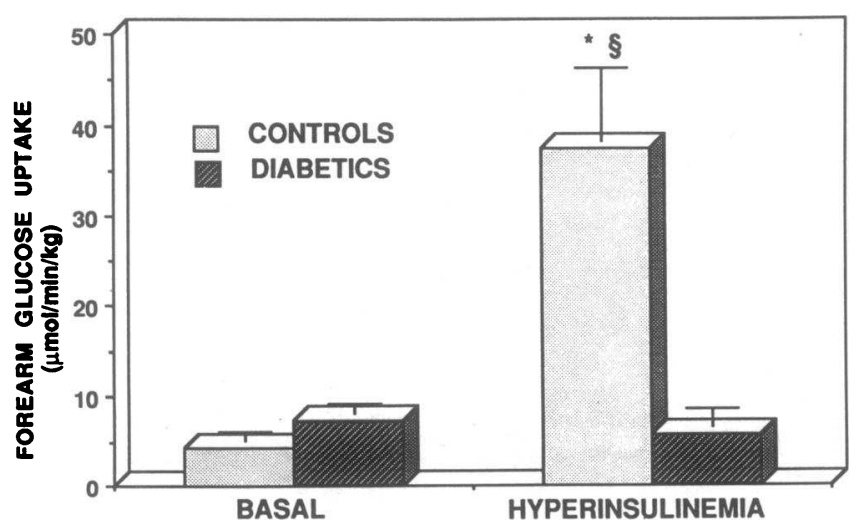

Figure 3. Forearm glucose uptake in control (stippled bars) and non-insulin-dependent diabetic (hatched bars) subjects at baseline and after physiologic hyperinsulinemia ( $\sim 500$ pmol/liter $).{ }^{*} P$ $<0.01$ vs. respective baseline; ${ }^{8} P<0.02$ vs. diabetic group.

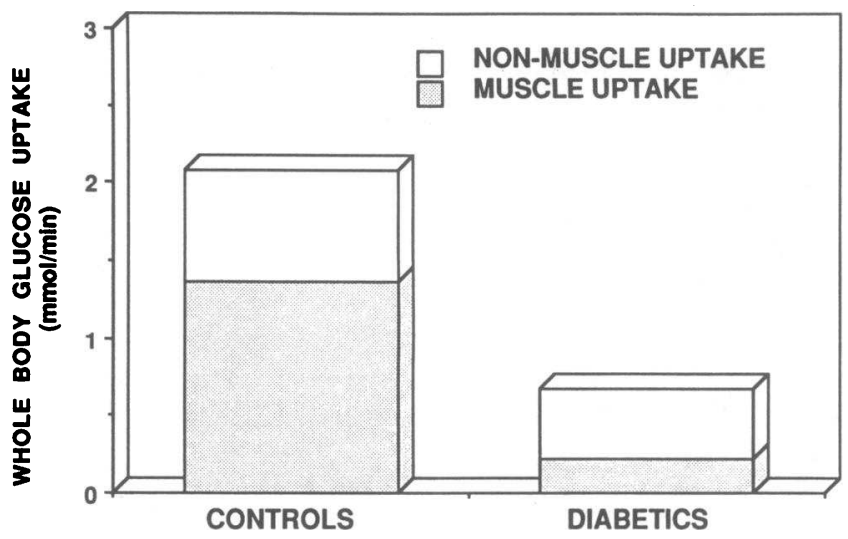

Figure 4. Estimated contribution of skeletal muscle (stippled portion of the column) to total glucose uptake (entire column) in controls (left) and non-insulin-dependent diabetics (right) after physiologic hyperinsulinemia. The data are not normalized per body weight because the index of adiposity (BMI; see Table I) and the body weight (data not shown) were similar in the two groups.

$<0.001$ vs. baseline value), but remained unchanged in NIDDM patients $(5.84 \pm 1.51 \mu \mathrm{mol} / \mathrm{min}$ per $\mathrm{kg}, P<0.02 \mathrm{vs}$. controls) (Fig. 3). Forearm glucose uptake was extrapolated to the whole body level under the assumptions that $(a) \sim 80 \%$ of the forearm blood flow goes to muscle (42), and $(b)$ muscle represents $\sim 60 \%$ of the forearm volume (43) and $\sim 40 \%$ of the body weight (44) in both diabetic and nondiabetic individuals. By this extrapolation, skeletal muscle accounted for $\sim 81 \%$ of the defect in insulin sensitivity documented in the NIDDM patients (Fig. 4).

Transmembrane glucose transport. The basal rate constants for inward $\left(k_{\text {in }}\right)$ and outward $\left(k_{\text {out }}\right)$ transmembrane 3-Omethyl-D-glucose transport in skeletal muscle were similar in NIDDM patients and controls $\left(5.75 \times 10^{-2} \pm 1.35 \times 10^{-2}\right.$ vs. $5.93 \times 10^{-2} \pm 0.96 \times 10^{-2} \cdot \mathrm{min}^{-1}$ and $3.8 \times 10^{-2} \pm 0.92 \times 10^{-2}$ vs. $4.6 \times 10^{-2} \pm 0.9 \times 10^{-2} \cdot \mathrm{min}^{-1}$, respectively). During the insulin clamp, fractional inward transport of 3-O-methyl-Dglucose $\left(k_{\text {in }}\right)$ in muscle was significantly lower in diabetics than in controls $\left(6.5 \times 10^{-2} \pm 0.56 \times 10^{-2}\right.$ vs. $12.5 \times 10^{-2} \pm 1.5$ $\left.\times 10^{-2} \cdot \min ^{-1}, P<0.005\right)$, whereas $k_{\text {out }}$ was comparable in the two groups $\left(4.7 \times 10^{-2} \pm 0.7 \times 10^{-2}\right.$ vs. $5.25 \times 10^{-2} \pm 0.77$ $\left.\times 10^{-2} \cdot \min ^{-1}\right)$ (Fig. 5). Using the pooled data from NIDDM patients and controls, a positive correlation was found to exist between whole body glucose uptake, which measures insulin sensitivity, and transmembrane fractional inward transport of 3-O-methyl-D-glucose ( $r=0.941, P<0.001)$ (Fig. 6).

\section{Discussion}

Insulin resistance in NIDDM has been thoroughly investigated in the past by using a wealth of in vivo and in vitro techniques aiming at identifying the specific cellular site(s) responsible for tissue unresponsiveness to insulin. The issue is of considerable importance because insulin resistance is thought to play a triple role in the natural history of NIDDM: $(a)$ it precedes the emergence of NIDDM in subjects at risk $(45,46)$; $(b)$ it predicts the onset of the diabetic state in subjects with impaired glucose tolerance (47-49); and (c) it plays a role in inducing and/or sustaining hyperglycemia (1).

As transmembrane transport is the first step in glucose han- 


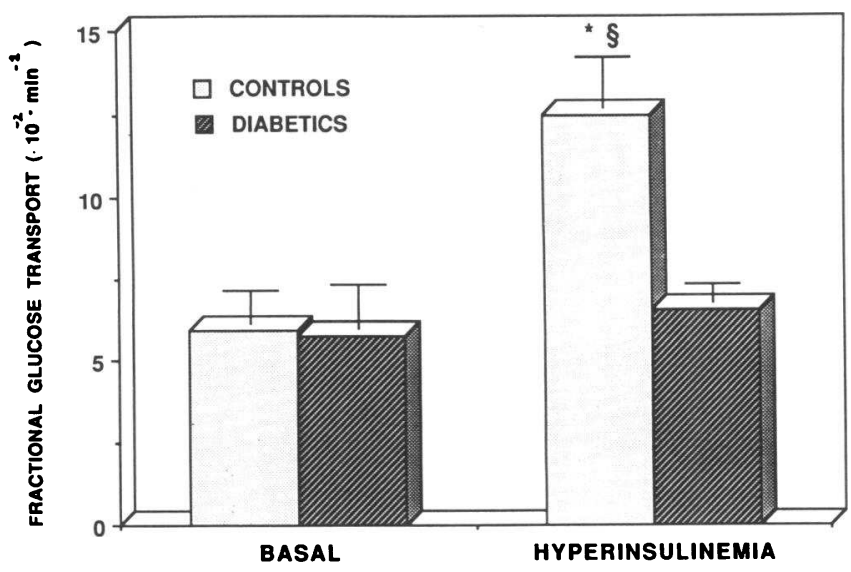

Figure 5. Transmembrane inward glucose transport in control (stippled bars) and non-insulin-dependent diabetic (hatched bars) subjects at baseline and after physiologic hyperinsulinemia $(\sim 500$ pmol/liter). ${ }^{*} P<0.01$ vs. respective baseline; ${ }^{\S} P<0.005$ vs. diabetic group.

dling by the cell and is regulated by insulin in insulin-sensitive tissues ( skeletal muscle, adipose tissue), specific attention has been devoted in the past to its function and regulation. Adipocytes have been the typical in vitro model to assess insulin sensitivity of glucose transport (50-52) because muscle tissue does not lend itself easily to in vitro study. However, the majority of a glucose load is disposed of by skeletal muscle (2-4, 53-56) and therefore the extrapolation of in vitro data in adipocytes to the in vivo situation in skeletal muscle may not be valid. Thus, in recent reports, glut 4 (the insulin-sensitive glucose transporter) content has been found to be decreased in adipocytes obtained from $\operatorname{NIDDM}$ patients $(57,58)$, but is usually normal in skeletal muscle (18-22).

In this context, obesity may be an additional confounding factor. Glucose transport in muscle strips from obese subjects with and without diabetes was shown to be unresponsive to insulin (16). In a group of nonobese diabetics, glucose transport in in vitro incubated muscle strips taken during elective abdominal surgery was found to be insulin resistant at supra-

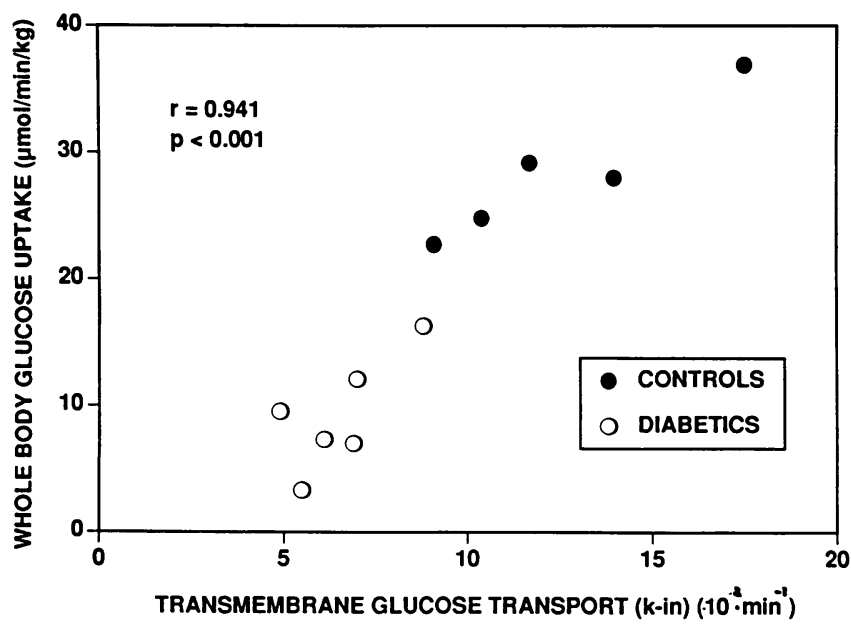

Figure 6. Correlation between whole body glucose disposal ( $y$ axis) and transmembrane glucose transport ( $x$ axis) in control (filled circles) and non-insulin-dependent diabetic (open circles) subjects after physiologic hyperinsulinemia. physiological insulin concentrations $(\geq 1,200 \mathrm{pM})$, whereas, at the only physiological concentration tested $(600 \mathrm{pM})$, the results were less easily interpretable because the insulin-induced stimulation above basal was of similar magnitude in the two groups, although the NIDDM patients displayed a 20\% decrease in the absolute value, which did not reach the statistical significance (17). In that study the NIDDM patients also were somewhat more obese than the controls, and obesity per se impairs glucose transport in in vitro incubated human muscle (16). Therefore, to answer the question whether insulin resistance of NIDDM conveys a defect in muscle glucose transport activity, it is necessary to investigate nonobese NIDDM patients at physiologic insulin concentrations.

In this study, using the forearm balance technique, we have been able to closely monitor the metabolic events occurring in vivo in human skeletal muscle. We show that skeletal muscle plays a primary role in the insulin resistance in NIDDM at the whole body level. These data are in agreement with previous studies by our laboratory $(2)$ and others $(3,4)$. We also show that, at high physiological insulin concentrations, no apparent insulin resistance in the metabolism of circulating FFA is present, because plasma FFA concentration is reduced to the same levels in both diabetics and controls. These data should not be considered at variance with an earlier study from our laboratory (30), because in this study insulin was infused overnight to normalize fasting glucose, thereby creating sustained hyperinsulinemia, which could ameliorate the subsequent response of circulating FFA to insulin.

The rate at which glucose is metabolized across a limb bed under steady-state conditions equals the rate of glucose phosphorylation by the cells ( 32 ). Therefore, the pathophysiologic meaning of both our data on forearm glucose uptake and previously published limb balance data (2-4) is that, after hyperinsulinemia, glucose phosphorylation is impaired in skeletal muscle of NIDDM patients. Shulman and colleagues recently demonstrated that glycogen formation, as quantitated by ${ }^{13} \mathrm{C}$ NMR in vivo spectroscopy, is a major fate of the glucose taken up by skeletal muscle and that glycogen synthesis is significantly depressed in NIDDM (59). Reduced glucose phosphorylation and glycogen synthesis in skeletal muscle are, therefore, documented defects in NIDDM.

Much attention has been devoted to glycogen synthase, and the activity of this enzyme has been found to be reduced in muscle biopsies obtained from patients with NIDDM (60-63). Much less information is presently available about muscle glucose transport and hexokinase activity in NIDDM patients at physiological insulin concentrations. Recently, Rothman et al. have measured in vivo glucose-6-phosphate concentration in skeletal muscle by ${ }^{31} \mathrm{P}-\mathrm{NMR}$ during hyperglycemic-hyperinsulinemic clamps and have provided experimental evidence that either glucose transport or glucose phosphorylation activity is impaired in NIDDM patients (64). Of particular concern is that, being located proximally to hexokinase and glycogen synthase, a defect in glucose transport could cause a reduction in both glucose phosphorylation and glycogen formation. Although the in vitro data would suggest that muscle glucose transport is likely to be impaired in NIDDM patients at physiologic insulin concentrations $(16,17,50-52)$, a direct assessment of in vivo muscle glucose transport activity is a necessary step in the elucidation of the pathophysiology of insulin resistance in NIDDM. When we began this study, no information was available on the activity of glucose transport in vivo in 
skeletal muscle of nonobese NIDDM patients. Furthermore, our dual tracer technique has the unique feature of being a direct in vivo measurement of glucose transport activity in human skeletal muscle $(23,24)$.

In examining transmembrane transport, which is inherently a nonlinear process (33), it is mandatory that the plasma glucose concentration be the same across different study groups and experimental maneuvers in order to allow meaningful comparisons. This was the rationale for bringing the elevated glucose levels down to control values in our NIDDM patients by means of a low-dose intravenous overnight insulin infusion. Under these baseline conditions, in the postabsorptive state, our NIDDM patients exhibited rates of glucose phosphorylation and transmembrane transport that were similar to those found in control subjects. However, it should be noted that euglycemia was obtained and maintained in NIDDM patients at the expense of a fourfold higher $(\sim 170 \mathrm{pmol} /$ liter $)$ peripheral insulin concentration compared with controls. In a previous study, we have shown that peripheral insulin levels in the range of 150-200 pmol/liter are indeed effective in stimulating glucose transport above the baseline value in young healthy individuals (24). We do not know whether such a phenomenon occurred in our NIDDM patients during the overnight insulin infusion. At any rate, normal transmembrane glucose transport in skeletal muscle is an accompanying feature of normalizing postabsorptive glucose homeostasis in NIDDM patients by administering insulin. Whether it plays any important pathophysiological role in restoring postabsorptive euglycemia in NIDDM remains an unsettled issue.

The most important finding of this study is that after physiologic hyperinsulinemia and concomitant with a reduced rate of glucose phosphorylation, fractional inward glucose transport was decreased by $\sim 48 \%$ in nonobese NIDDM patients. Previous reports, by showing that transmembrane glucose transport is impaired in in vitro preparation of human fat cells taken from NIDDM patients (50-52) pointed to glucose transport as a major candidate step for causing insulin resistance in skeletal muscle. Nevertheless, this is the first demonstration in vivo of a specific defect in glucose transport in human skeletal muscle of nonobese, non-insulin-dependent diabetic patients. Furthermore, as a confirmation and an extension of our previous results $(23,24)$, there was a good correlation between whole body glucose disposal rate and transmembrane glucose transport in human skeletal muscle during physiologic hyperinsulinemia (Fig. 6). Stated otherwise, the more insulin resistant an individual is, the less active glucose transport is in skeletal muscle.

In this study, we report that in NIDDM patients during euglycemic hyperinsulinemia, forearm glucose uptake and transmembrane inward glucose transport activity are, respectively, $\sim 16$ and $\sim 52 \%$ of the values measured in the controls. Furthermore, in the passage from the basal to the hyperinsulinemic state, our control subjects exhibited a sevenfold increase in forearm glucose uptake, but only doubled fractional glucose transport. These findings are at odds with the widespread belief that a one-to-one relationship should hold between cellular transmembrane glucose transport and forearm glucose uptake. However, forearm glucose uptake, under steady-state conditions, is the net balance between transmembrane inward and outward glucose transport rates, and, as such, represents a low bond for inward glucose transport. Yki-Jarvinen et al. have shown that the $V_{\max }$ and the $K_{\mathrm{m}}$ of forearm glucose uptake are, respectively, $\sim 44 \mu \mathrm{mol} / \mathrm{min}$ per $\mathrm{kg}$ and $\sim 7.4 \mathrm{mM}(54)$. As forearm glucose uptake is the low boundary for glucose transport, their findings imply that at a 5-mM glucose concentration transmembrane inward glucose transport should be no less than $18 \mu \mathrm{mol} / \mathrm{min}$ per $\mathrm{kg}$. A twofold increase of this minimal estimate of glucose transport would be sufficient to sustain the rate of forearm glucose uptake observed by us in the control group. Moreover, as, according to our data, the fold increase in glucose transport (approximately twofold) is less than in forearm glucose uptake (approximately sevenfold), it is predicted that intracellular glucose concentration should fall in skeletal muscle of normal individuals after hyperinsulinemia. SchalinJantti et al. have recently reported that intracellular glucose concentration is indeed decreased in skeletal muscle biopsies taken from healthy individuals during a euglycemic insulin clamp at physiologic insulin concentrations (65). Thus, our results are compatible with the available evidence on the role of glucose transport activity in determining muscle glucose metabolism in vivo in healthy humans and document that in vivo glucose transport is impaired in skeletal muscle of nonobese NIDDM patients.

The latter finding has some important implications. First, it shows that in the biochemical cascade that leads to reduced glucose phosphorylation and glycogen formation in NIDDM patients, transmembrane glucose transport is the first and most proximal effector to be impaired, and as such is a major determinant of peripheral insulin resistance in NIDDM. This does not rule out the existence of one or more additional defects located at more distal steps in intracellular glucose metabolism, such as, for instance, glycogen synthase (60-63).

Second, there is experimental evidence that in adipocytes of NIDDM patients, where glucose transport is known to be decreased (50-52), glut 4 levels are reduced $(57,58)$. Thus, in human adipocytes there is a parallel behavior between glut 4 content and glucose transport activity. Most recent data have shown that glut 4 levels in skeletal muscle of nonobese NIDDM subjects are normal (18-22). Therefore, if the concomitant changes in glut 4 levels and transmembrane glucose transport documented in human adipocytes in vitro were a paradigm for the pathophysiology of glucose transport in human skeletal muscle in vivo, glucose transport in the latter tissue should be normal in NIDDM patients and should not be a component of insulin resistance in vivo. We show, instead, that glucose transport is insulin resistant in vivo in skeletal muscle of nonobese, non-insulin-dependent diabetics. As this insulin insensitivity is not caused by a decreased concentration of glut 4 (18-22), it must be due to a defect in the intrinsic activity and/or the translocation to the plasma membrane of the glucose transporters (10-15). This emphasizes the need for further investigations in this area. Furthermore, future extrapolations from the in vitro findings in adipocytes to the in vivo pathophysiology of glucose transport in human skeletal muscle should be undertaken with special caution because, at least in human NIDDM, the two tissues show a different behavior.

Third, our observations raise the fundamental question of whether this defect in muscle glucose transport develops subsequent to the onset of hyperglycemia (1) or precedes it, thereby being an inherent characteristic of insulin resistance in NIDDM patients even before hyperglycemia ensues.

Experimental evidence in favor of the former hypothesis has been provided both in vivo in the intact rat (66) and in in vitro preparations $(67-70)$ in which high glucose levels have 
been shown to desensitize transmembrane glucose transport to the stimulatory action of insulin. In addition, in human type 1 diabetes mellitus, hyperglycemia has been shown to be a cause of insulin resistance (71). A corollary of the former hypothesis is that the defect in glucose transport should be ameliorated by strict glycemic control. Transmembrane glucose transport was, indeed, improved in adipocytes taken from NIDDM patients after treatment with insulin to improve glycemic control (72). To our knowledge, no data are available to substantiate or reject this hypothesis in human muscle.

As for the latter hypothesis, the only data in its support are from the study of relatives of NIDDM patients, who, at a time of preserved glucose homeostasis, display insulin resistance of a degree not very different from that seen in overt diabetics $(45$, 46). However, it is unknown whether in those individuals transmembrane glucose transport in skeletal muscle is impaired.

In summary, we have shown that transmembrane glucose transport is insulin resistant in the skeletal muscle of NIDDM patients and that this impairment is approximately proportional to their degree of insulin resistance. Since the content of the insulin-sensitive glucose transporter (glut 4) in muscle is not affected by NIDDM (18-22), a defect in translocation and/or intrinsic activity of glut 4 may be present in nonobese NIDDM patients. Whether this defect precedes or follows the onset of hyperglycemia remains to be determined.

\section{Acknowledgments}

The authors wish to thank Rita Mirabelli, Debra Mitchell, and Barbara Washington for the highly competent nursing care of the volunteers. Christopher Carroll, Howard Christophersson, Anna Crowder, and Ronald Klein provided superb technical assistance.

This work was supported in part by National Institutes of Health grants DK-24092, DK-20579, RR-00954, and HD-20805, a Veterans Administration (VA) Merit Award, General Clinical Research Center grant M01-RR-01346, funds from the VA Medical Research Service and Geriatric Research Education and Clinical Center, and a grant from the Italian Ministero dell'Università e della Ricerca Scientifica e Tecnologica (40\%). R. C. Bonadonna was the recipient of a fellowship from the Juvenile Diabetes Foundation International (No. 388041). M. P. Saccomani was partly supported by the Resource Facility for Kinetic Analysis, University of Washington, Seattle, WA.

\section{References}

1. DeFronzo, R. A. 1988 . The triumvirate: $\beta$-cell, muscle, liver: a collusion responsible for NIDDM. Diabetes. 37:667-683.

2. DeFronzo, R. A., R. Gunnarsson, O. Bjorkman, M. Olsson, and J. Wahren 1985. Effects of insulin on peripheral and splanchnic glucose metabolism in non-insulin dependent (type II) diabetes mellitus. J. Clin. Invest. 76:149-155.

3. Capaldo, B., R. Napoli, L. Di Marino, A. Picardi, G. Riccardi, and L. Saccà. 1988. Quantification of forearm glucose and free fatty acid (FFA) disposal in normal subjects and type II diabetic patients: evidence against an essential role for FFA in the pathogenesis of insulin resistance. J. Clin. Endocrinol. Metab. 67:893-898

4. Baron, A. D., M. Laakso, G. Brechtel, and S. V. Edelman. 1991. Reduced capacity and affinity of skeletal muscle for insulin-mediated glucose uptake in noninsulin-dependent diabetic subjects. Effects of insulin therapy. J. Clin. Invest. 87:1186-1194.

5. Kayano, T., H. Fukumoto, R. L. Eddy, Y. Fan, M. G. Byers, T. N. Shows, and G. I. Bell. 1988. Evidence for a family of human glucose transporter-like proteins. J. Biol. Chem. 263:15245-15248.

6. Fukumoto, H., T. Kayano, J. B. Buse, Y. Edwards, P. F. Pilch, G. I. Bell, and S. Seino. 1989. Cloning and characterization of the major insulin-responsive glucose transporter expressed in human skeletal muscle and other insulin-responsive tissues. J. Biol. Chem. 264:7776-7779.

7. Birnbaum, M. J. 1989. Identification of a novel gene encoding an insulinresponsive glucose transporter protein. Cell. 57:305-315.
8. James, D. E., M. Strube, and M. Mueckler. 1989. Molecular cloning and characterization of an insulin-regulatable glucose transporter. Nature (Lond.). 33:83-87.

9. Charron, M. J., F. C. Brosius, S. L. Alper, and H. F. Lodish. 1989. A glucose transport protein expressed predominantly in insulin-responsive tissues. Proc. Natl. Acad. Sci. USA. 86:2535-2539.

10. Cushman, S., and L. Wardzala. 1980. Potential mechanism of insulin action on glucose transport in the isolated rat adipose cell: apparent translocation of intra-cellular transport system to the plasma membrane. J. Biol. Chem. 255:4758-4762.

11. Suzuki, K., and T. Kono. 1980. Evidence that insulin causes translocation of glucose transport activity to the plasma membrane from an intracellular storage site. Proc. Natl. Acad. Sci. USA. 77:2542-2545.

12. Baly, D. L., and R. Horuk. 1987. Dissociation of insulin-stimulated glucose transport from the translocation of glucose carriers in rat adipose cells. $J$. Biol. Chem. 262:21-24.

13. Toyoda, N., J. E. Flanagan, and T. Kono. 1987. Reassessment of insulin effects on the $V_{\max }$ and $K_{\mathrm{m}}$ values of hexose transport in isolated rat epididymal adipocytes. J. Biol. Chem. 262:2737-2745.

14. Sternlicht, E., R. J. Barnard, and G. K. Grimdtich. 1988. Mechanism of insulin action on glucose transport in rat skeletal muscle. Am. J. Physiol. 254:E633-638.

15. Joost, H. G., T. M. Weber, and S. W. Cushman. 1988. Qualitative and quantitative comparison of glucose transport activity and glucose transporter concentration in plasma membranes from basal and insulin-stimulated rat adipose cells. Biochem. J. 249:155-161.

16. Dohm, G. L., E. B. Tapscott, W. J. Pories, D. J. Dabbs, E. G. Flickinger, D. Meelheim, T. Fushiki, S. M. Atkinson, C. W. Elton, and J. F. Caro. 1988. An in vitro human muscle preparation suitable for metabolic studies. Decreased insulin stimulation of glucose transport in muscle from morbidly obese and diabetic subjects. J. Clin. Invest. 82:486-494.

17. Andréasson, K., D. Galuska, A. Thorne, T. Sonnenfeld, and H. WallbergHenriksson. 1991. Decreased insulin-stimulated 3- $O$-methylglucose transport in in vitro incubated muscle strips from type II diabetic subjects. Acta Physiol. Scand. 142:255-260.

18. Pedersen, O., J. F. Bak, P. H. Andersen, S. Lund, D. E. Moller, J. S. Flier, and B. B. Kahn. 1990. Evidence against altered expression of GLUT1 or GLUT4 in skeletal muscle of patients with obesity or NIDDM. Diabetes. 39:865-870.

19. Handberg, A. A., A. Vaag, P. Damsbo, H. Beck-Nielsen, and J. Vinten. 1990. Expression of insulin regulatable glucose transporters in skeletal muscle from type 2 (non-insulin-dependent) diabetic patients. Diabetologia. 33:625627.

20. Dohm, G. L., C. W. Elton, J. E. Friedman, P. F. Pilch, W. J. Pories, S. M Atkinson, Jr., and J. F. Caro. 1991. Decreased expression of glucose transporter in muscle from insulin-resistant patients. Am. J. Physiol. 260:E459-E463.

21. Eriksson, J., L. Koranyi, R. Bourey, C. Schalin-Jantti, E. Widen, M. Mueckler, A. M. Permutt, and L. C. Groop. 1992. Insulin-resistance in type 2 (non-insulin-dependent) diabetic patients and their relatives is not associated with a defect in the expression of the insulin-responsive glucose transporter (GLUT-4) gene in human skeletal muscle. Diabetologia. 35:143-147.

22. Garvey, W. T., L. Maianu, J. A. Hancock, A. M. Golichowski, and A. Baron. 1992. Gene expression of GLUT4 in skeletal muscle from insulin-resistant patients with obesity, IGT, GDM, and NIDDM. Diabetes. 41:465-475.

23. Cobelli, C., M. P. Saccomani, E. Ferrannini, R. A. DeFronzo, R. Gelfand, and R. C. Bonadonna. 1989. A compartmental model to quantitate in vivo glucose transport in the human forearm. Am. J. Physiol. 257:E943-E958.

24. Bonadonna, R. C., M. P. Saccomani, L. Seely, K. Zych, E. Ferrannini, C. Cobelli, and R. A. DeFronzo. 1993. Glucose transport in human skeletal muscle: the in vivo response to insulin. Diabetes. 42:191-198.

25. National Diabetes Data Group. 1979. Classification and diagnosis of diabetes mellitus and other categories of glucose intolerance. Diabetes. 28:10391057.

26. Coles, D. R., K. E. Cooper, R. F. Mottram, and O. V. Occleshaw. 1958. The source of blood samples withdrawn from deep forearm veins via catheters passed upstream from the median cubital vein. J. Physiol. (Lond.). 142:258-267.

27. DeFronzo, R. A., J. D. Tobin, and R. Andres. 1979. The glucose clamp technique: a method for the quantification of beta cell sensitivity to glucose and of tissue sensitivity to insulin. Am. J. Physiol. 237:E214-E223.

28. Gelfand, R. A., and E. J. Barrett. 1987. Effect of physiologic hyperinsulinemia on skeletal muscle protein synthesis and breakdown in man. J. Clin. Invest. 80:1-7.

29. DeFronzo, R. A., E. Ferrannini, R. Hendler, P. Felig, and J. Wahren. 1983. Regulation of splanchnic and peripheral glucose uptake by insulin and hyperglycemia in man. Diabetes. 32:35-45.

30. Groop, L. C., R. C. Bonadonna, S. Del Prato, K. Ratheiser, K. Zych, E. Ferrannini, and R. A. DeFronzo. 1989. Glucose and free fatty acid metabolism in non-insulin-dependent diabetes mellitus. Evidence for multiple sites of insulin resistance. J. Clin. Invest. 84:205-213.

31. Dillon, R. S. 1965. Importance of hematocrit in interpretation of blood sugar. Diabetes. 14:672-674. 
32. Zierler, K. L. 1961. Theory of the use of arteriovenous concentration differences for measuring metabolism in steady and non-steady state. J. Clin. Invest. 40:2111-2125.

33. Carruthers, A. 1990. Facilitated diffusion of glucose. Physiol. Rev. 70:1135-1176.

34. Bassingthwaighte, J. B., and C. A. Goresky. 1984. Modeling in the analysis of solute and water exchange in the microvasculature. In Handbook of Physiology. The Cardiovascular System. Microcirculation. Section 2, Vol. 4, Chap. 13. American Physiological Society, Bethesda, MD. 549-626.

35. Kuikka, J., M. Levin, and J. B. Bassingthwaighte. 1986. Multiple tracer dilution estimates of D- and 2-deoxy-D-glucose uptake by the heart. Am. J. Physiol. 250:H29-H40.

36. Sorenson, J. A., and M. E. Phelps. 1987. Physics in Nuclear Medicine. 2nd ed. W. B. Saunders Company, Philadelphia, PA. 500-502.

37. Bonadonna, R. C., M. P. Saccomani, C. Cobelli, and R. A. DeFronzo. 1993. Effect of insulin on system A amino acid transport. J. Clin. Invest. 91:514521.

38. Berman, M., W. F. Beltz, P. C. Gries, R. Chabay, and R. C. Boston. 1983. CONSAM User's Guide. National Institutes of Health, Bethesda, MD. 92 pp.

39. Berman, M., and M. F. Weiss. 1978. SAAM Manual. National Institutes of Health, Bethesda, MD. 120 pp.

40. Carson, E. R., C. Cobelli, and L. Finkelstein. 1983. The Mathematical Modeling of Metabolic and Endocrine Systems. John Wiley \& Sons, Inc., New York. 394 pp.

41. Zar, J. 1984. Biostatistical Analysis. Prentice Hall, Englewood Cliffs, NJ. $718 \mathrm{pp}$.

42. Cooper, K., O. Edholm, and R. Mottram. 1955. The blood flow in skin and muscle of the human forearm. J. Physiol. (Lond.). 128:258-267.

43. Maughan, R. J., J. S. Watson, and J. Weir. 1984. The relative proportions of fat, muscle and bone in the normal human forearm as determined by computed tomography. Clin. Sci. 66:683-689.

44. Clarys, J. P., A. F. Martin, and D. T. Frinkwater. 1984. Gross tissue weights in the human body by cadaver dissection. Hum. Biol. 56:459-473.

45. Eriksson, J., A. Franssila-Kallunki, A. Edstrand, C. Saloranta, E. Widen, C. Schalin, and L. C. Groop. 1989. Early metabolic defects in persons at increased risk of non-insulin-dependent diabetes mellitus. $N$. Engl. J. Med. 321:337-343.

46. Gulli, G., E. Ferrannini, M. Stern, S. Haffner, and R. A. DeFronzo. 1992. The metabolic profile of NIDDM is fully established in glucose-tolerant offspring of two Mexican-American NIDDM parents. Diabetes. 41:1575-1586.

47. Bogardus, C., S. Lillioja, J. Foley, L. Christin, D. Freymond, B. Nyomba, P. H. Bennett, G. Reaven, and L. Salans. 1987. Insulin resistance predicts the development of non-insulin dependent diabetes mellitus in Pima Indians. Diabetes. 36(Suppl. 1):47A. (Abstr.)

48. Knowler, W. C., D. J. Pettitt, M. F. Saad, and P. H. Bennett. 1990.

Diabetes mellitus in the Pima Indians: incidence, risk factors and pathogenesis. Diabetes Metab. Rev. 6:1-27.

49. Saad, M. F., W. C. Knowler, D. J. Pettitt, R. G. Nelson, D. M. Mott, and P. H. Bennett. 1988. The natural history of impaired glucose tolerance in Pima Indians. N. Engl. J. Med. 319:1500-1506.

50. Ciaraldi, T. P., O. G. Kolterman, J. A. Scarlett, and J. M. Olef ky. 1982. Role of glucose transport in the post-receptor defect of non-insulin-dependent diabetes mellitus. Diabetes. 31:1016-1022.

51. Foley, J. E., P. Thuillez, S. Lillioja, J. Zawadzki, and C. Bogardus. 1986. Insulin sensitivity in adipocytes from subjects with varying degrees of glucose tolerance. Am. J. Physiol. 251:E306-E310.

52. Garvey, T. W., T. P. Hueckstadt, S. Matthaei, and J. M. Olefsky. 1988. Role of glucose transporters in the insulin resistance of type II non-insulin-dependent diabetes mellitus. J. Clin. Invest. 81:1528-1536.

53. DeFronzo, R. A., E. Jacot, E. Jequier, E. Maeder, J. Wahren, and J. P. Felber. 1981. The effects of insulin on the disposal of intravenous glucose: results from indirect calorimetry and hepatic and femoral venous catheterization. Diabetes. 30:1000-1007.
54. Yki-Jarvinen, H., A. A. Young, C. Lamkin, and J. E. Foley. 1987. Kinetics of glucose disposal in whole body and across the forearm in man. J. Clin. Invest. 79:1713-1719.

55. Katz, L., M. G. Glickman, S. Rapoport, E. Ferrannini, and R. A. DeFronzo. 1983. Splanchnic and peripheral disposal of oral glucose in man. Diabetes. 32:675-679.

56. Mitrakou, A., D. Kelley, T. Veneman, T. Jenssen, T. Pangburn, J. Reilly, and J. Gerich. 1990. Contribution of abnormal muscle and liver glucose metabolism to postprandial hyperglycemia in NIDDM. Diabetes. 39:1381-1390.

57. Garvey, T. W., L. Maianu, T. P. Hueckstadt, M. J. Birnbaum, J. M. Molina, and T. P. Ciaraldi. 1991. Pretranslational suppression of a glucose transporter protein causes insulin resistance in adipocytes from patients with non-insulin-dependent diabetes mellitus and obesity. J. Clin. Invest. 87:1072-1081.

58. Sinha, M. K., C. Raineri-Maldonado, C. Buchanan, W. J. Pories, C. Carter-Su, P. F. Pilch, and J. F. Caro. 1991. Adipose tissue glucose transporters in NIDDM: decreased levels of muscle/fat isoform. Diabetes. 40:472-477.

59. Shulman, G. I., D. L. Rothman, T. Jue, P. Stein, R. A. DeFronzo, and R. G. Shulman. 1990. Quantitation of muscle glycogen synthesis in normal subjects and subjects with non-insulin-dependent diabetes by ${ }^{13} \mathrm{C}$ nuclear magnetic resonance spectroscopy. $N$. Engl. J. Med. 322:223-228.

60. Bogardus, C., S. Lillioja, K. Stone, and D. Mott. 1984. Correlation between muscle glycogen synthase activity and in vivo insulin action in man. $J$. Clin. Invest. 73:1185-1190.

61. Kida, Y., A. Esposito-Del Puente, C. Bogardus, and D. M. Mott. 1990. Insulin resistance is associated with reduced fasting and insulin-stimulated glycogen synthase phosphatase activity in human skeletal muscle. J. Clin. Invest. 85:476-481.

62. Kelley, D. E., and L. J. Mandarino. 1990. Hyperglycemia normalizes insulin-stimulated skeletal muscle glucose oxidation and storage in noninsulindependent diabetes mellitus. J. Clin. Invest. 86:1999-2007.

63. Thornburn, A. W., B. Gumbiner, F. Bulacan, G. Brechtel, and R. R. Henry. 1991. Multiple defects in muscle glycogen synthase activity contribute to reduced glycogen synthesis in non-insulin dependent diabetes mellitus. J. Clin. Invest. 87:489-495.

64. Rothman, D. L., R. G. Shulman, and G. I. Shulman. 1992. ${ }^{31} \mathrm{P}$ nuclear magnetic resonance measurements of muscle glucose-6-phosphate. Evidence for reduced insulin-dependent muscle glucose transport or phosphorylation activity. J. Clin. Invest. 89:1069-1075.

65. Schalin-Jantti, C., M. Harkonen, and L. C. Groop. 1992. Impaired activation of glycogen synthase in people at increased risk for developing NIDDM. Diabetes. 41:598-604.

66. Rossetti, L., J. D. Smith, G. I. Shulman, D. Papachristou, and R. A. DeFronzo. 1987. Correction of hyperglycemia with phloridzin normalizes tissue sensitivity to insulin in diabetic rats. J. Clin. Invest. 79:1510-1515.

67. Sasson, S., and E. Cerasi. 1986. Substrate regulation of the glucose transport system in rat skeletal muscle. J. Biol. Chem. 261:16827-16833.

68. Sasson, S., D. Edelson, and E. Cerasi. 1987. In vitro autoregulation of glucose utilization in rat soleus muscle. Diabetes. 36:1041-1046.

69. Garvey, W. T., J. M. Olefsky, S. Matthaei, and S. Marshall. 1987. Glucose and insulin co-regulate the glucose transport system in primary cultured adipocytes. J. Biol. Chem. 262:189-197.

70. Richter, E. A., B. F. Hansen, and S. A. Hansen. 1988. Glucose-induced insulin resistance of skeletal muscle glucose transport and uptake. Biochem. J. 252:733-737.

71. Yki-Jarvinen, H., E. Helve, and V. A. Koivisto. 1987. Hyperglycemia decreases glucose uptake in type I diabetes. Diabetes. 36:892-896.

72. Scarlett, J. A., O. G. Kolterman, T. O. Ciaraldi, M. Kao, and J. M. Olefsky. 1983. Insulin treatment reverses the postreceptor defect in adipocyte 3-O-methylglucose transport in type II diabetes mellitus. J. Clin. Endocrinol. Metab. 56:1195-1201 